\title{
Synthesis of $\mathrm{NaX}(\mathrm{X}=\mathrm{F}, \mathrm{Cl}, \mathrm{Br}, \mathrm{I})$ Nanoparticles
}

\author{
Elseddik Abdelkader, Steven W. Buckner*
}

Department of Chemistry, Saint Louis University, St. Louis, USA.

Email: "buckners@slu.edu

Received October $24^{\text {th }}, 2012$; revised November $31^{\text {st }}, 2012$; accepted December $15^{\text {th }}, 2012$

\begin{abstract}
We report here on the synthesis of nanoparticles (NPs) of sodium halide $(\mathrm{NaX} ; \mathrm{X}=\mathrm{F}, \mathrm{Cl}, \mathrm{Br}$, I) salts using reverse micelles (water/dioctylsodiumsulfosuccinate/toluene) with the resulting NPs having diameters of 1.5 to $2.5 \mathrm{~nm}$. The initial core of reverse micelle contains a water-soluble salt. After evaporation of the volatile compounds under vacuum (water and toluene), NaX NPs are produced with an AOT surfactant cap. The NaX NPs redisperse in toluene. In contrast to previous syntheses of soluble salt NPs, $\mathrm{Na}^{+}$ions from the surfactant are found to completely exchange with the salt in the initial core of the reverse micelles. The resulting NPs were analyzed with dynamic light scattering (DLS), transmission electron microscopy (TEM), and selected area electron diffraction (SAED) which confirmed the exchange mechanism. Experimental results are compared and found to be in agreement with the recently published model by Bandopadhyaya and coworkers.
\end{abstract}

Keywords: Alkali Halides Nanoparticles; Reverse Micelles; Modeling; Synthesis

\section{Introduction}

Nanoparticle (NP) synthesis is very important in many areas including biomedicine [1], fuel cells [2], data storage [3], ceramics [4] and electronics [5]. There are numerous useful NP synthetic techniques including lithography [6], electrochemistry [7], arrested precipitation [8], hydrothermal synthesis [9] and reverse micelles [10]. Arrested precipitation, hydrothermal reactions, and reverse micellar methods all use some method of controlled precipitation reaction of appropriate precursors to produce binary and ternary ionic compound NPs. These methods generally require the NP product materials to have very low solubility such that the free energy for formation of the binary or ternary system from the precursors is very large. Formation of NPs of soluble binary and ternary systems has been accomplished, primarily through the use of reverse micelles. In general, reverse micelle NP synthesis is carried out by mixing different micellar dispersions with appropriate reactants in their aqueous phase which results in a spatially confined reaction producing nanocrystalline products. Cationic (e.g. AOT [11] and SDS [12]), anionic (e.g. CTAB [13] and DDAB [14]) and nonionic (e.g. TEOS [15] and Brij30 [16]) surfacetants have all been successfully employed for nanomaterials synthesis. NPs synthesized using this technique include metals (e.g. Ag) [17]' bimetallics (e.g. Au/Pd) [18] alloys (e.g. $\mathrm{Pt}_{3} \mathrm{Co}$ ) [19], nanocomposites (e.g. Dye/Gold hybrid) [20] and semiconductors (e.g. PbS) [21-23].

"Corresponding author.
These systems are based on either reduction reactions (for metal nanostructures) or precipitation reactions (for semiconductors) where the micellar diffusion and intermicellar exchange lead to contact and reaction [24]. Precipitation is successfully used to prepare a wide range of water-insoluble or sparingly-soluble salts for many binary and ternary NP systems. A modification of this method was first reported by Turco Liveri and coworkers for the synthesis of NPs of some soluble salts. Their basic method involved preparation of micelle solutions of the corresponding salts, followed by evaporation of solvents from the solutions. This resulted in precipitation of the soluble salt from solution during solvent evaporation. Using this method, NPs of $\mathrm{Cu}\left(\mathrm{NO}_{3}\right)_{2}, \mathrm{Na}_{2} \mathrm{HPO}_{4}$ [24], $\mathrm{CaCl}_{2}$ [25], $\mathrm{Na}_{2} \mathrm{~S}$ and $\mathrm{ZnSO}_{4}$ [26] have been achieved. The resulting NPs were capped with the surfactant that allows redispersion in dry organic solvents. Bandyopadhyaya and coworkers (RSB) have developed a model to describe this process. They supported their model with experiments conducted on the $\mathrm{CaCl}_{2}$ system [25]. Ions in the incipient saturated solution precipitated on the surfactant head groups during the evaporation process. Their model allows prediction of product NP diameter based on a variety of factors, including ion concentration, $\mathrm{w}_{0}$, and micelle concentration.

In this work, we report on the synthesis of NPs for the water-soluble group I halides using the reverse micelle method. The system was composed of sodium bis-(2ethylhexyl)-sulfosuccinate (AOT)/toluene/water and an 
aqueous core was consisting of one of the alkali metal halide salts. Characterization of the resulting NPs was accomplished with transmission electron microscopy (TEM), selected area electron diffraction (SAED) and dynamic light scattering (DLS). In contrast to previous work, we observe exchange of surfactant's sodium ions with cations in the solute. We also observe much smaller NP diameters than previously reported using other synthetic methods. We compared our NP product sizes with the RSB model and find agreement for these smaller sizes.

\section{Experimental Methods}

Toluene (anhydrous, 99.8\%), inorganic salts (NaX; $\mathrm{X}=\mathrm{F}$, $\mathrm{Cl}, \mathrm{Br}, \mathrm{I}$ and $\mathrm{LiX}, \mathrm{KX}, \mathrm{RbX} ; \mathrm{X}=\mathrm{Cl}$ ) were purchased from Sigma. AOT (sodium bis-(2-ethylhexyl)-sulfosuccinate, anhydrous) was purchased from Fischer. Nanopure water was used in all experiments. All chemicals were used as received. The ternary system of $0.10 \mathrm{M}$ salt/AOT/toluene was used to produce the reverse micelles. In a typical experiment, $9.0 \mu \mathrm{l}$ of $1.0 \mathrm{M}$ salt solution were added to $5.00 \mathrm{ml}$ of $0.100 \mathrm{M} \mathrm{AOT/toluene} \mathrm{so-}$ lution to generate micellar solution with $\mathrm{w}_{0}=1.0\left(\mathrm{w}_{0}=\right.$ $\left[\mathrm{H}_{2} \mathrm{O}\right] /[\mathrm{AOT}]$ ). The resulting solution was sonicated (Fischer Scientific Ultrasonic Cleaner FS30D) for two hours to ensure complete dispersion of the salt solution into micelles. The micelle solution was then transferred to a Schlenk tube where the solvent and the water were removed en vacuo. The solution was heated $\left(70^{\circ} \mathrm{C}-80^{\circ} \mathrm{C}\right)$ to speed the evaporation, which typically required 15 20 minutes for completion. After complete evaporation of the solvent, a white gel-like precipitate containing AOT-coated salt NPs was formed. This solid matrix was left under vacuum overnight to ensure complete drying of the sample. The solid matrix was redissolved completely in the hydrocarbon solvent to make a translucent solution of AOT-capped NaX NPs. A concentrated solution of NPs was dispersed in toluene for analysis with dynamic light scattering (DLS). DLS measurements were performed on a Malvern Nano-ZS zetasizer (Malvern Instruments Ltd., Worcestershire, UK). Samples ( 1.0 ml) were taken from the Schlenk tubes and filtered with a syringe. The filtrate was placed into a cuvette (Wildman quartz UV spectrophotometer cell (1/10) for analysis. DLS scans were run at $25^{\circ} \mathrm{C}$. Each data point was an average of 12 scans.

Resuspension of NPs in toluene was used for characterization by transmission electron microscopy (TEM) images and selected area electron diffraction (SAED). Analysis was obtained by a Phillips EM430 TEM operating at $300 \mathrm{keV}$ using $\mathrm{Cu}$ grids with a lacy support film at $25,000 \times-81,000 \times$ magnification. UV-Vis spectra were obtained using Shimadzu 2501PC UV-Vis absorption spectrometer. Luminescence spectra were obtained on a Photon Technologies QM 4-2003 fluorescence spectrophotometer.

\section{Results and Discussion}

Water-soluble halides dissociate in water to give ions according to reaction (1).

$$
\mathrm{NaX}(\mathrm{s}) \rightleftarrows \mathrm{Na}^{+} \text {(aq.) }+\mathrm{X}^{-} \text {(aq.) }
$$

Using Le Chatelier's principle, the driving force behind formation of sodium halides NPs or any watersoluble particles is the removal of water by evaporation from a confined space (the reverse micelle) which allows the size control. As a result, salt concentration inside the micellar solution increases beyond the saturation concentration which leads to formation of NPs by either homogeneous or heterogeneous nucleation. After formation, surfactant molecules, which coat the NPs by adsorption, stabilize the particles toward aggregation and agglomeration.

Results for $\mathrm{NaX}(\mathrm{X}=\mathrm{F}, \mathrm{Cl}, \mathrm{Br}, \mathrm{I}) \mathrm{NPs}$ produced with $\mathrm{w}_{0}=1$ are given in Table 1. DLS particle size distributions are shown in Figure 1.

The sizes of the NPs measured with DLS and the corresponding number of formula units per NP is not statistically different proceeding down the various halides. All the NP diameters are in the 1.5 to $2.5 \mathrm{~nm}$ range. These NPs are significantly smaller than those previously reported for soluble binary compounds [25]. Solubility product values $\left(\mathrm{K}_{\mathrm{sp}} \mathrm{M}^{2}\right)$ increase going from fluoride to iodide. The Gibbs free energy $\left(\Delta \mathrm{G}^{\circ} \mathrm{kJ} / \mathrm{mol}\right)$ for the precipitation reaction was also calculated and the values follow the same trend as $\mathrm{K}_{\mathrm{sp}}$ values.

While NP size and sometimes shape [27] are typically affected by $\mathrm{w}_{0}$, we saw a small size-dependence on $\mathrm{w}_{0}$ over the narrow range that we studied ( 0.5 to 3$)$ as shown in Table 2. However, the error bars on size distribution cloud the differences over this narrow range of $\mathrm{w}_{0}$.

TEM and SAED images are shown in Figure 2. The TEM images are for small groups of particles in islands on the TEM grid. SAED served to qualitatively identify the NPs synthesized. The diffraction patterns shown in Figure 2 are for diffraction from single NPs. Thus, the distance from the central spot to the spot of a particular set of planes gives the d-spacing for that set of planes in the crystal structure. SAED for the NPs shown are consistent with sodium fluoride, chloride and bromide (Figures 2(a), (b) and (c) respectively). The numbers next to the spots on the patterns (e.g. 111 or 222) designate the set of planes that each spot represents.

Synthesis of the other group I alkali chlorides was attempted using $\mathrm{LiCl}, \mathrm{KCl}$, and $\mathrm{RbCl}$. In these cases the corresponding salts were dissolved and prepared with AOT analogously to the NaX NPs. However, SAED shows that the product NPs are all consistent only with 


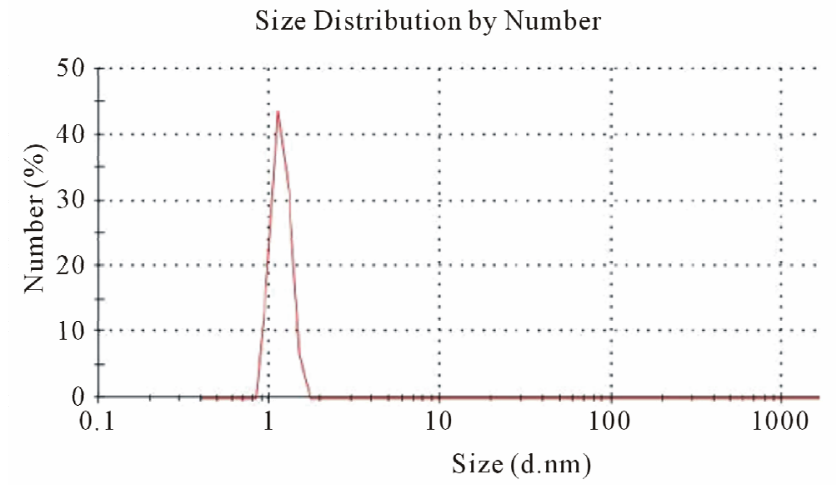

Record 42:NaF 1

Size Distribution by Number

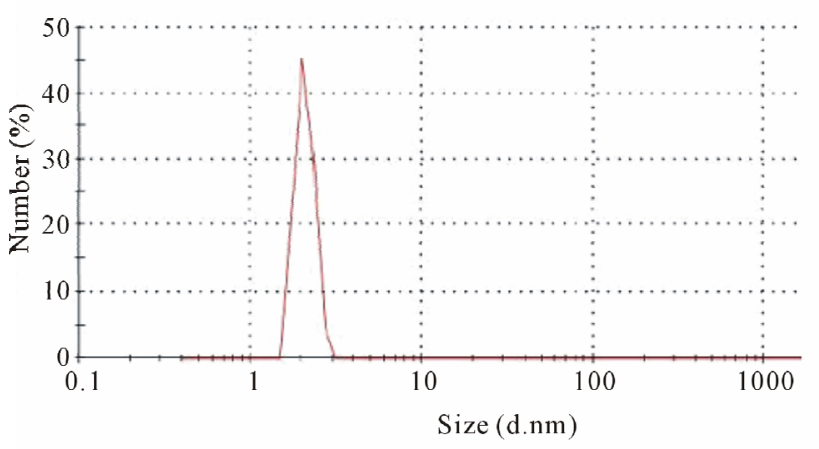

Record 39:NaBr I
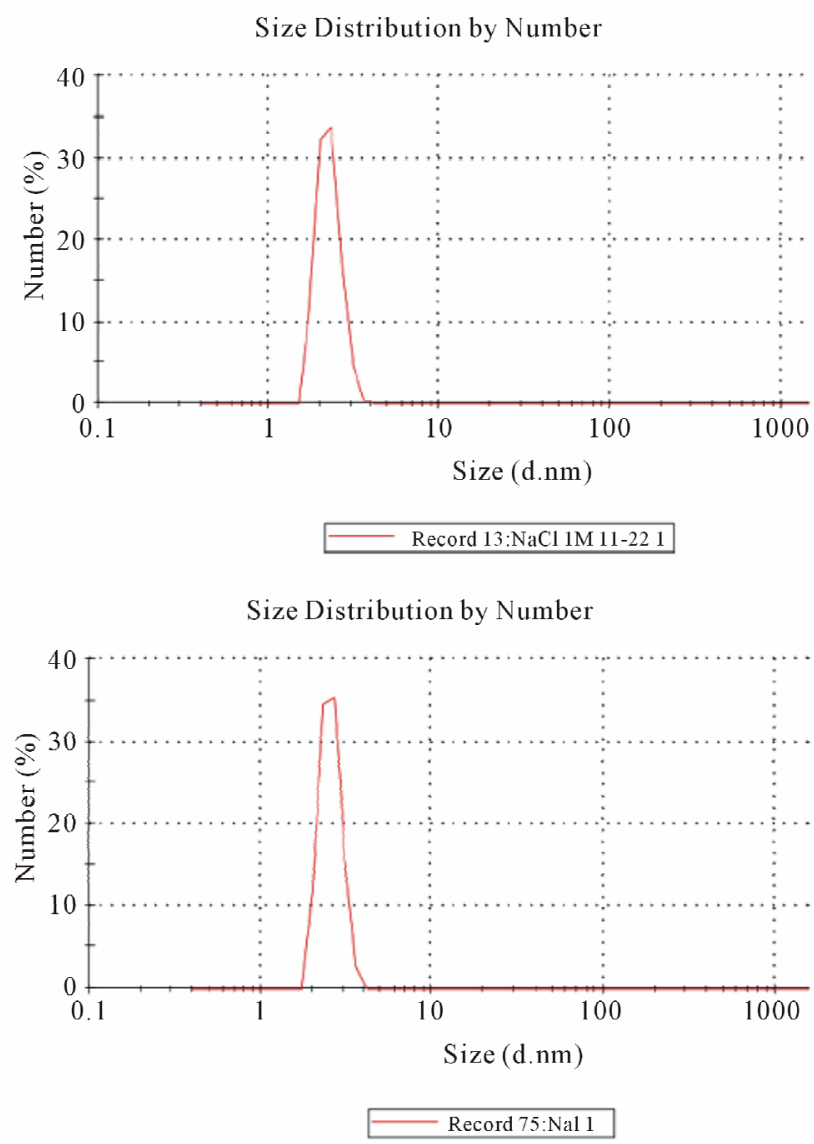

Figure 1. Particle size distribution of sodium salt NPs using DLS.

Table 1. Sizes of Sodium Halide NPs measured with DLS, where $D$ is diameter $(\mathrm{nm})$, SD (standard deviation), F.U. (number of formula units/NP), $\zeta$ (zeta potential).

\begin{tabular}{cccccc}
\hline $\mathrm{NaX}$ & $\mathrm{D} \pm \mathrm{SD}$ & F.U. & $\zeta(\mathrm{mv})$ & $\mathrm{K}_{\mathrm{sp}}$ & $\Delta \mathrm{G}^{\circ}$ \\
\hline $\mathrm{NaF}$ & $1.5 \pm 0.6$ & 73 & -12.5 & 0.25 & 0.001 \\
$\mathrm{NaCl}$ & $2.2 \pm 0.5$ & 124 & -10.7 & 38 & 9.0 \\
$\mathrm{NaBr}$ & $2.3 \pm 0.2$ & 124 & -14.6 & 77 & 10.8 \\
$\mathrm{NaI}$ & $2.5 \pm 0.4$ & 118 & -15.7 & 151 & 12.4 \\
\hline
\end{tabular}

Table 2. Sizes of NaCI NPs measured with DLS.

\begin{tabular}{ccc}
\hline $\mathrm{w}_{0}($ molar ratio) & Diameter $(\mathrm{nm})$ & $\mathrm{SD}$ \\
\hline 0.50 & 2.7 & 0.6 \\
1.0 & 2.2 & 0.5 \\
3.0 & 2.3 & 0.2 \\
\hline
\end{tabular}

$\mathrm{NaCl}$. Clearly, the $\mathrm{Na}^{+}$in AOT, which was in $>50$-fold molar excess, exchanged with the alkali metal cations inside the micelles prior to evaporation. For the current conditions, the surfactant concentration (and hence, $\left[\mathrm{Na}^{+}\right]$) was $0.100 \mathrm{M}$ while the total $[\mathrm{MX}]$ in the dispersion (and hence, $\left[\mathrm{M}^{+}\right]$, with $\mathrm{M}=\mathrm{Li}, \mathrm{K}, \mathrm{Rb}$ ) was $1.8 \mathrm{mM}$. This type of exchange chemistry was not reported previously during the synthesis of other water-soluble NPs like $\mathrm{CaCl}_{2}$ [25] and $\mathrm{ZnSO}_{4}$ [26]. The only monovalent cation salts previously reported were with $\mathrm{Na}^{+}$and so this exchange chemistry would not have been evident in the presence of an $\mathrm{Na}^{+}$-containing surfactant. The exchange chemistry with $\mathrm{M}^{+}$that we observed may be due to the ease of exchange between $\mathrm{Na}^{+}$and monovalent cations from group I compared to divalent cations in case of calcium chloride and zinc sulfate. In previous studies the nucleation on surfactant head groups, was favored for divalent cations like $\mathrm{Ca}^{2+}$ and $\mathrm{Zn}^{2+}$. The divalent ions' higher charge makes them bind more tightly to the anionic head group of the surfactant. Once nucleation begins with the divalent ion, the subsequent growth will favor the divalent ions. Further, charge balance within the micelle favors the exchange between monovalent ions rather than the exchange of monovalent ions for divalent ions.

\section{Model for NP Growth}

Heterogeneous nucleation has a lower saturation threshold than homogeneous nucleation due to lower activation energy. This is the mechanism proposed by RSB in their 


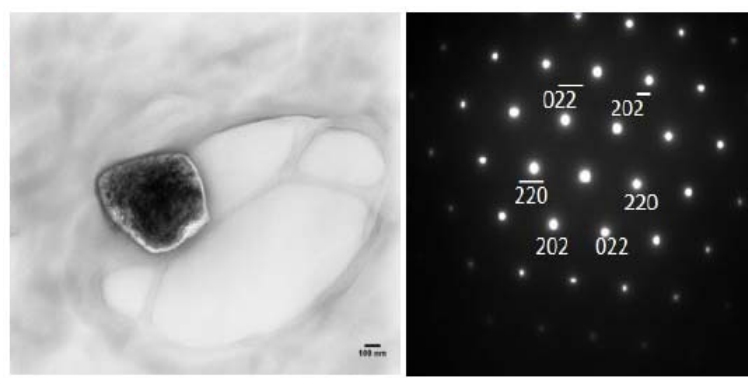

(a)

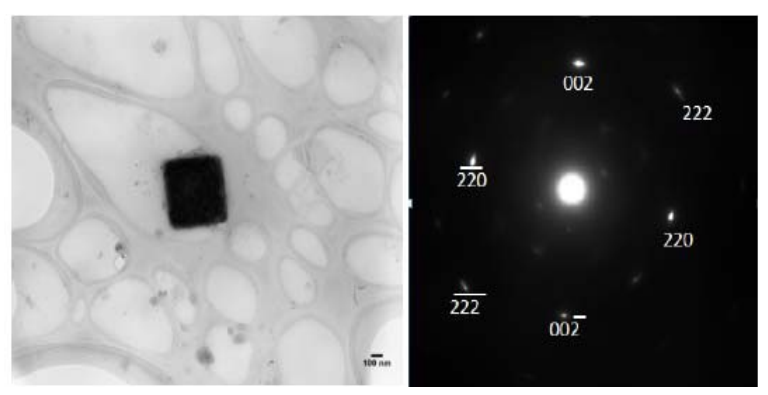

(b)

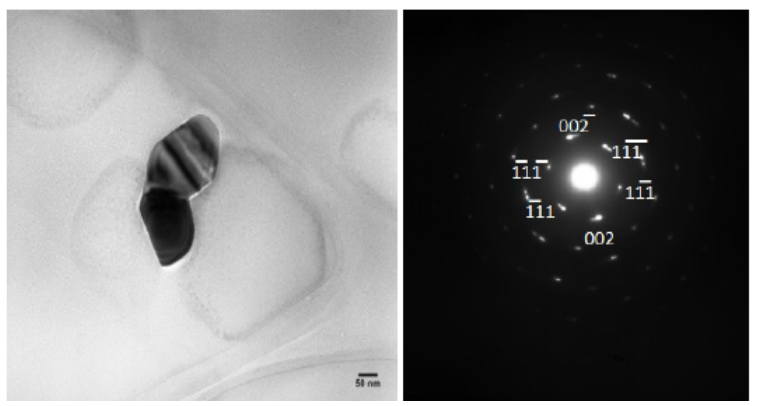

(c)

Figure 2. TEM and SAED of (a) $\mathrm{NaF}$ (b) $\mathrm{NaCl}$ (c) $\mathrm{NaBr}$ at $\mathrm{w}_{0}=1$. Note the TEM images contain a group of NaX NPs aggregated on the TEM grid. SAED are for single particles.

recent study of $\mathrm{CaCl}_{2} \mathrm{NP}$ formation using water-in-oil (w/o) microemulsion system [28]. According to their model; nucleation occurs in a droplet and is initiated by a surfactant headgroup. Only a limited number of micelles initiate nucleation with further growth of the nucleus into a NP by diffusion of nearby droplets providing $\mathrm{Ca}^{2+}$ and $\mathrm{Cl}^{-}$ions in order to give further growth. Thus, growth to the final NP is determined by diffusion of micelles from a contributing region. The diameter of the NP $\left(\mathrm{d}_{\mathrm{NP}}\right)$ produced upon solvent evaporation from the dispersion is given by RSB as in Equation (1):

$$
\mathrm{d}_{\mathrm{NP}}=\frac{\left[(2 \mathrm{x})^{3} \mathrm{~N}_{\mathrm{drop}} \mathrm{n}_{\mathrm{m}} \mathrm{M}_{\mathrm{W}}\right]^{1 / 3}}{\mathrm{~N}_{\mathrm{A}} \rho_{M X}}
$$

with $\mathrm{x}$ as the radius of the contributing region, $\mathrm{N}_{\text {drop }}$ as the concentration of micelles in the dispersion, $\mathrm{n}_{\mathrm{m}}$ as the number of $\mathrm{MX}$ formula units per micelle, $\mathrm{M}_{\mathrm{W}}$ as the mo- lecular weight for MX, $\mathrm{N}_{\mathrm{A}}$ as Avogadro's number, and $\rho_{\mathrm{MX}}$ as the density of MX. For our current system with $\mathrm{w}_{0}$ $=1.0$ for $\mathrm{NaCl}$ and a solute concentration of $[\mathrm{NaCl}]=1.0$ $\mathrm{M}$, the radius of the contributing region of micelles is $3.01 \times 10^{-8} \mathrm{~m}$. In this contributing region the average micelle contains $0.63 \mathrm{NaCl}$ formula units. Thus, the region encompasses, on average, 197 micelles. This provides $124 \mathrm{NaCl}$ formula units, in agreement with the experimental results in Table 1 for $\mathrm{NaCl}$ NPs produced with $\mathrm{w}_{0}=1.0$ and analyzed with DLS.

In order to calculate $\mathrm{x}$, the RBS model uses the Einstein-Smoluchowski equation to relate back to the time, $t$, for the mean square displacement within the contributing region, Equation (2):

$$
\mathrm{x}^{2}=6 \mathrm{Dt}
$$

with $\mathrm{D}$ as the diffusion coefficient. Time $\mathrm{t}$ is then obtained as follows:

$$
\begin{aligned}
\mathrm{t}=1 / \mathrm{K}_{\text {hetero }} & \mathrm{K}_{\text {hetero }}= \\
& \frac{2 \pi \mathrm{r}^{3} \mathrm{pdr}^{*}}{3 \mathrm{Rv}_{\mathrm{w}}\left(\mathrm{n}^{*}\right)^{2 / 3}} \exp \\
& -\left(\frac{16\left[\pi \sigma_{\mathrm{nw}}^{3} \mathrm{v}_{\mathrm{m}}^{2}\right]^{1 / 3}\left(3 \mathrm{n}^{*}\right)^{2 / 3} f(\theta)}{3\left(\mathrm{~K}_{\mathrm{B}} \mathrm{T}\right)(32)^{2 / 3}}\right)
\end{aligned}
$$

All the terms in Equations (2)-(4) along with the values we used for the $\mathrm{NaCl} \mathrm{NP}$ system are shown in Table 3. Based on these equations and using $n^{*}=1.5$ (which depends on $\mathrm{w}_{0}$ that is lower in our system than RSB), the model predicts a $\mathrm{NaCl} \mathrm{NP}$ diameter of $2.26 \mathrm{~nm}$. This is consistent with the observed mean of the size distribution measured from our DLS measurements of $2.2(+0.5) \mathrm{nm}$.

Table 4 presents results for the calculation of $\mathrm{NaCl} \mathrm{NP}$ sizes for all three $\mathrm{w}_{0}$ values along with the experimental results for each. There is agreement between the RSB model and the experimental results in general. But at the smallest $\mathrm{w}_{0}$, the model predicts a smaller NP diameter probably due to the extremely small size of both NP and $\mathrm{w}_{0}$. At these small $\mathrm{w}_{0}$ and NP sizes there is no detectable dependence of $\mathrm{w}_{0}$ on the resulting NP diameter within experimental error.

\section{Conclusion}

In present work, we demonstrate synthesis of sodium halide NPs with sizes less than $3 \mathrm{~nm}$ using the reverse micelle approach. Characterization of NPs was performed by TEM, SAED and DLS. NP size was found to be weakly dependent on $\mathrm{w}_{0}$ values. We noted that using AOT as a surfactant is not suitable for synthesizing all the alkali metal halides because of the exchange chemistry between the sodium ion in AOT and the alkali metal cations. No defect or trap state emission was observed in the luminescence of these NaX NPs. 
Table 3. Parameters used in calculation of NaCl NP sizes.

\begin{tabular}{|c|c|c|}
\hline Variable & Definition & Value \\
\hline $\mathrm{D}[25]$ & $\begin{array}{l}\text { Drop's diffusion coef- } \\
\text { ficient }\end{array}$ & $5.77 \mathrm{E}-10 \mathrm{~m}^{2} \cdot \mathrm{s}^{-1}$ \\
\hline d & $\mathrm{NaX}$ diffusivity & $1.2 \mathrm{E}-10 \mathrm{~m}^{2} \mathrm{~s}^{-1}$ \\
\hline$f(\Theta)[25]$ & $\begin{array}{l}\text { Factor estimated by } \\
\text { approximating the } \\
\text { surfactant head-groups } \\
\text { as part of a continuous } \\
\text { flat surface }\end{array}$ & 0.93 \\
\hline $\mathrm{k}_{\mathrm{B}}$ & $\begin{array}{l}\text { Boltzmann's } \\
\text { constant }\end{array}$ & $1.3806 \mathrm{E}-23 \mathrm{~J} \mathrm{~K}^{-1}$ \\
\hline$K_{\text {hetero }}[25]$ & $\begin{array}{l}\mathrm{NaX} \text { heterogeneous } \\
\text { nucleation rate }\end{array}$ & $3.62 \mathrm{E}-6 \mathrm{~s}^{-1}$ \\
\hline $\mathrm{n}^{*}$ & $\begin{array}{c}\text { Critical number of } \mathrm{NaX} \\
\text { molecules to form a } \\
\text { nucleus }\end{array}$ & 1.5 \\
\hline $\mathrm{R}$ & [Water]/[surfactant] & 1 \\
\hline $\mathrm{r}^{*}$ & $\begin{array}{l}\text { NaX critical radius of } \\
\text { nucleus }\end{array}$ & $2.52 \mathrm{E}-10 \mathrm{~m}$ \\
\hline r [25] & Drop radius & $1.8 \mathrm{R}+4.5 \AA(6.3 \AA)$ \\
\hline $\mathrm{T}$ & Temperature & $298 \mathrm{~K}$ \\
\hline $\mathrm{v}_{\mathrm{m}}$ & $\begin{array}{l}\text { Volume of } \mathrm{NaX} \\
\text { molecule }\end{array}$ & $4.48 \mathrm{E}-29 \mathrm{~m}^{3}$ \\
\hline $\mathrm{v}_{\mathrm{w}}[25]$ & $\begin{array}{l}\text { Volume of water } \\
\text { molecule }\end{array}$ & $2.99 \mathrm{E}-29 \mathrm{~m}^{3}$ \\
\hline$\mu_{\mathrm{h}}$ & Solvent's viscosity & $0.0006 \mathrm{Kg} / \mathrm{ms}$ \\
\hline$\rho$ & $\mathrm{NaX}$ density per drop & $6.022 \mathrm{E}+26 \mathrm{~m}^{-3}$ \\
\hline$\sigma_{\mathrm{nw}}[28]$ & $\begin{array}{l}\text { Interfacial tension } \\
\text { between nucleus and } \\
\text { water }\end{array}$ & $0.07 \mathrm{~N} / \mathrm{m}$ \\
\hline
\end{tabular}

Table 4. Calculated NaCl NP diameters as a function of $\mathbf{w}_{0}$.

\begin{tabular}{ccc}
\hline $\mathrm{w}_{0}$ (molar ratio) & Calculated $\mathrm{d}_{\mathrm{NP}}(\mathrm{nm})$ & Experimental $\mathrm{d}_{\mathrm{NP}}(\mathrm{nm})$ \\
\hline 0.5 & 1.73 & $2.7 \pm 0.6$ \\
1.0 & 2.26 & $2.2 \pm 0.5$ \\
3.0 & 2.28 & $2.3 \pm 0.2$ \\
\hline
\end{tabular}

\section{Acknowledgements}

We acknowledge Saint Louis University office of research services for support of this work. E.A acknowledges Brandon Thomas and Ashish Patel for helpful discussions.

\section{REFERENCES}

[1] J. Gao, H. Gu and B. Xu, "Multifunctional Magnetic Nanoparticles: Design, Synthesis, and Biomedical Appli- cations," Accounts of Chemical Research, Vol. 42, No. 8, 2009, pp. 1097-1107. doi:10.1021/ar9000026

[2] K. Matsuoka, K. Miyazaki, Y. Iriyama, K. Kikuchi, T. Abe and Z. Ogumi, "Novel Anode Catalyst Containing Gold Nanoparticles for Use in Direct Methanol Fuel Cells," Journal of Physical Chemistry C, Vol. 111, No. 7, 2007, pp. 3171-3174. doi:10.1021/jp065440c

[3] D. Wan, H. L. Chen, S. C. Tseng, L. A. Wang and Y. P. Chen, "One-Shot Deep-UV Pulsed-Laser-Induced Photomodification of Hollow Metal Nanoparticles for HighDensity Data Storage on Flexible Substrates," ACS Nano, Vol. 4, No. 1, 2010, pp. 165-173. doi:10.1021/nn9013005

[4] J. Rose, M. M. Cortalezzi-Fidalgo, S. Moustier, C. Magnetto, C. D. Jones, A. R. Barron, M. R. Wiesner and J.-Y. Bottero, "Synthesis and Characterization of CarboxylateFeOOH Nanoparticles (Ferroxanes) and Ferroxane-Derived Ceramics," Chemistry of Materials, Vol. 14, No. 14, 2002, pp. 621-628. doi:10.1021/cm010583r

[5] S. H. Ko, I. Park, H. Pan, C. P. Grigoropoulos, A. P. Pisano, C. K. Luscombe and J. M. J. Frechet, "Direct Nanoimprinting of Metal Nanoparticles for Nanoscale Electronics Fabrication," Nano Letters, Vol. 7, No. 7, 2007, pp. 1869-1877. doi:10.1021/n1070333v

[6] L. R. Giam, S. He, N. E. Horwitz, D. J. Eichelsdoerfer, J. Chai, Z. Zheng, D. Kim, W. Shim and C. A. Mirkin, "Positionally Defined, Binary Semiconductor Nanoparticles Synthesized by Scanning Probe Block Copolymer Lithography," Nano Letters, Vol. 12, No. 2, 2012, pp. 1022 1025. doi: $10.1021 / \mathrm{nl} 204233 \mathrm{r}$

[7] L. Rodriguez-Sanchez, M. C. Blanco and M. A. LopezQuintela, "Electrochemical Synthesis of Silver Nanoparticles," Journal of Physical Chemistry B, Vol. 104, No. 41, 2000, pp. 9683-9688. doi:10.1021/jp001761r

[8] J. Tang, F. Redl, Y. Zhu, T. Siegrist, L. E. Brus and M. L. Steigerwald, "An Organometallic Synthesis of $\mathrm{TiO}_{2}$ Nanoparticles," Nano Letters, Vol. 5, No. 3, 2005, pp. 543-548. doi:10.1021/n1047992h

[9] J. V. Williams, C. N. Adams, N. A. Kotov and P. E. Savage, "Hydrothermal Synthesis of CdSe Nanoparticles," Industrial \& Engineering Chemistry Research, Vol. 46, No. 46, 2007, pp. 4358-4362. doi:10.1021/ie061413x

[10] V. Uskokovic and M. Drofenik, "Synthesis of Materials within Reverse Micelles," Surface Review and Letters, Vol. 12, No. 2, 2005, pp. 239-277. doi:10.1142/S0218625X05007001

[11] J. P. Cason, M. E. Miller, J. B. Thompson and C. B. Roberts, "Solvent Effects on Copper Nanoparticle Growth Behavior in AOT Reverse Micelle Systems," Journal of Physical Chemistry B, Vol. 105, No. 12, 2001, pp. 22972302. doi: $10.1021 / \mathrm{jp} 002127 \mathrm{~g}$

[12] I. G. Zigoneanu, C. E. Astete and C. M. Sabliov, "Nanoparticles with Entrapped $\alpha$-Tocopherol: Synthesis, Characterization, and Controlled Release," Nanotechnology, Vol. 19, No. 10, 2008, pp. 1-8. doi:10.1088/0957-4484/19/10/105606

[13] W. Wang, X. Tian, K. Chen and G. Cao, "Synthesis and Characterization of Pt-Cu Bimetallic Alloy Nanoparticles by Reverse Micelles Method," Colloids and Surfaces A, 
Vol. 273, No. 1-3, 2006, pp. 35-42. doi:10.1016/j.colsurfa.2005.07.029

[14] M. Taguchi, K. Yamada, K. Suzuki, O. Sato and Y. Einaga, "Photoswitchable Magnetic Nanoparticles of Prussian Blue with Amphiphilic Azobenzene," Chemistry of Materials, Vol. 17, No. 17, 2005, pp. 4554-4559. doi: $10.1021 / \mathrm{cm} 051060 \mathrm{c}$

[15] D. B. Zhang, H. M. Cheng, J. M. Ma, Y. P. Wang and X. Z. Gai, "Synthesis of Silver-Coated Silica Nanoparticles in Nonionic Reverse Micelles," Journal of Materials Science Letters, Vol. 20, No. 5, 2001, pp. 439-440. doi:10.1023/A:1010906615079

[16] D. Dodoo-Arhin, M. Leoni, P. Scardi, E. Garnier and A. Mittiga, "Synthesis, Characterisation and Stability of $\mathrm{Cu}_{2} \mathrm{O}$ Nanoparticles Produced via Reverse Micelles Microemulsion," Materials Chemistry and Physics, Vol. 122, No. 2-3, 2010, pp. 602-608. doi:10.1016/j.matchemphys.2010.03.053

[17] P. Setua, A. Chakraborty, D. Seth, M. U. Bhatta, P. V. Satyam and N. Sarkar, "Synthesis, Optical Properties, and Surface Enhanced Raman Scattering of Silver Nanoparticles in Nonaqueous Methanol Reverse Micelles," Journal of Physical Chemistry C, Vol. 111, No. 10, 2007, pp. 3901-3907. doi:10.1021/jp067475i

[18] M.-L. Wu, D.-H. Chen and T.-C. Huang, "Synthesis of $\mathrm{Au} / \mathrm{Pd}$ Bimetallic Nanoparticles in Reverse Micelles," Langmuir, Vol. 17, No. 13, 2001, pp. 3877-3883. doi:10.1021/1a010060y

[19] Z. Liu, C. Yu, I. A. Rusakova, D. Huang and P. Strasser, "Synthesis of Pt3Co Alloy Nanocatalyst via Reverse Micelle for Oxygen Reduction Reaction in PEMFCs," Topics in Catalysis, Vol. 49, No. 3-4, 2008, pp. 241-250. doi:10.1007/s11244-008-9083-2

[20] M. Takahashi, S. Ohno, N. Fujita, T. Sengoku and H. Yoda, "Reverse Micellar Synthesis of Dye/Gold Hybrid Nanocomposites," Chemistry Letters, Vol. 39, No. 5, 2010, pp. 504-505. doi:10.1246/c1.2010.504

[21] Q. Wu, N. Zheng, Y. Ding and Y. Li, "Micelle-Template
Inducing Synthesis of Winding ZnS Nanowires," Inorganic Chemistry Communications, Vol. 5, No. 9, 2002, pp. 671-673. doi:10.1016/S1387-7003(02)00523-3

[22] V. T. K. Lien, C. V. Ha, L. T. Ha and N. N. Dat, "Optical Properties of CdS and CdS/ZnS Quantum Dots Synthesized by Reverse Micelle Method," Journal of Physics: Conference Series, Vol. 187, No. 1, 2009, Article ID: 012028. doi:10.1088/1742-6596/187/1/012028

[23] S. W. Buckner, R. L. Konold and P. A. Jelliss, "Luminescence Quenching in PbS Nanoparticles," Chemical Physics Letters, Vol. 394, No. 4-6, 2004, pp. 400-404. doi:10.1016/j.cplett.2004.06.138

[24] V. Marciano, A. Minore and V. T. Liveri, "A Simple Method to Prepare Solid Nanoparticles of Water-Soluble Salts Using Water-in-Oil Microemulsions," Colloid \& Polymer Science, Vol. 278, No. 3, 2000, pp. 250-252. doi:10.1007/s003960050039

[25] C. Ravikumar, S. K. Singh and R. Bandyopadhyaya, "Formation of Nanoparticles of Water-Soluble Molecules: Experiments and Mechanism," Journal of Physical Chemistry $C$, Vol. 114, No. 19, 2010, pp. 8806-8813. doi:10.1021/jp1009934

[26] P. Calandra, A. Longo and V. T. Liveri, "Preparation and Characterisation of $\mathrm{NA}_{2} \mathrm{~S}$ and $\mathrm{ZnSO}_{4}$ Nanoparticles in Water/Sodium bis(2-ethylhexyl)sulphosuccinate/n-heptane microemulsions," Colloid \& Polymer Science, Vol. 279, No. 11, 2001, pp. 1112-1117. doi:10.1007/s003960100540

[27] G. D. Rees, R. Evans-Gowing, S. J. Hammond and B. H. Robinson, "Formation and Morphology of Calcium Sulfate Nanoparticles and Nanowires in Water-in-Oil Microemulsions," Langmuir, Vol. 15, No. 6, 1999, pp. 19932002. doi:10.1021/la981026v

[28] R. Bahadur, L. M. Russell and S. Alavi, "Surface Tensions in NaCl-Water-Air Systems from MD Simulations," Journal of Physical Chemistry B, Vol. 111, No. 41, 2007, pp. 11989-11996. doi:10.1021/jp075356c 